experiments, it is suggested that lycopod powder mixed with sugar and water is a good material, as the lycopod spores are easily detected.

It is self-evident that if the mouth-apparatus of the fly will admit of the introduction of such objects as have been above noted, that there will be no difficulty in its adnitting scores of the spores of many parasitic fungi, and above all of those belonging to the Schizomycetes, the possible cause of so much disease. Already has Dr. Grassi detected in fly excrement the spores of Oidium lactis, and the spores of a Botrytis, this latter taken from the bodies of silkworms dead of muscardine.

There arises, of course, the question of how far the active digestion in the intestines of the flies may not destroy the vitality of germs or spores thus taken in, but it would seem probable that in many instances the larger bodies swallowed may not serve as objects for assimilation, but may be got rid of as foreign bodies, and it will be borne in mind that the flies themselves fall victims to the growth of a parasitic fungus (Empusa musca, Cohn), which is probably taken first into their own stomachs.

Dr. Grassi promises to publish the results of his experiments in fuller detail. Judging of their interest by this abstract, they will well deserve to be followed up, and though in these countries our modern sanitary arrangements do not tend to the development of such immense swarms of flies as are so constantly to be met with in Italy, still the dangers to be apprehended from them there are possibly, though in a less degree, to be encountered here, and the investigation of the fact is easy to any one possessing a fairly average microscope and the power of catching a fly.

E. P. W.

\section{EDINBURGH MARINE STATION} $\mathrm{A}^{\mathrm{T}}$ the half-yearly meeting of the Scottish Meterrosubmitted a statement on the work done by the Fisheries Committee. This included preliminary reports from the Rev. A. M. Norman on the invertebrate fauna of the Scottish fresh-water lochs; Prof. Herdman's report of his researches connected with the fi heries of Loch Fyne, and similar reports from Messrs. Hoyle and Bed Aard from Peterhead and Eyemouth. After reading several interesting extracts from these reports, which will shortly appear in the Society's Journal, he then stated that the marine station at Granton would be formally opened for scientific work about the roth of next month by Prof. Haeckel of Jena. The floating laboratory, which has been named the $A r k$, was successfully launched on Saturday last, and it has accommodation for seven biologists. The steam yacht of thirty tons, which is to be called the Medusa, is to be launched on the $26 \mathrm{th}$ inst. at Glasgow, and will be at the station ten days thereafter.

The Station will then be possessed of the three most important requisites, viz. the floating laboratory, with abundance of sea water; a steam vessel fitted with all modern appliances for sounding, dredging, and other biological and physical investigations; and lastly, a most complete library in marine biology and physics. Mr. J. T. Cunningham, B.A. Oxon., Fellow of University College, Oxford, has been appointed Naturalist in charge of the Station; Mr. Hugh Robert Mill, B.Sc., who holds a Research Fellowship in the University of Edinburgh, is to carry on physical and meteorological investigations under the superintendence of Prof. Tait; Mr. Alexander Turbyne, fisherman, Keeper; Mr. William Bell, la:e Royal Navy, Engineer ; and it is hoped the arrangements will shortly be made that will enable a botanist and geologist to carry on systematic work at the Station. The captain of the yacht will be appointed next week.

British and foreign naturalists are invited to make use of the resources of the Station free of charge, and those who desire to do so are requested to communicate with
Mr. John Murray, Challenger Office, Edinburgh, stating the kind of work they propose to undertake and the length of time they will probably remain. Efforts are now being made to provide living accommodation for the naturalists and others who may be working at the Station. Immediately after the meeting Mr. Murray re ceived anonymously a donation of 1ool. towards the further equipment of the Station. We wish every success to this undertaking, and, from the liberal spirit shown in placing at the service of scientific men the unique facilities afforded by the Station for the prosecution of inquiries of the highest practical importance, we have every confidence that the public will not be slow in seeing that the funds required for its efficient maintenance are forthcoming.

\section{THE DEEP-SEA FISHES OF THE "TALISMAN"}

A MONG the many wonderful animal forms collected during the voyage of the Talisman none surpass the fishes in interest. In the exhibition, now open at the Jardin des Plantes, Paris, of the various specimens collected during this voyage, the collection of fishes holds a chief place. During the cruises of the Travailleur, owing to the apparatus employet, the capture of a fish was a rare event, but by the employment of a kind of drag-net on board the Talisman the number both of species and individuals taken was quite surprising. Once, on July 29 , in $16^{\circ} 52^{\prime} \mathrm{N}$. lat. and $27^{\circ} 50^{\prime} \mathrm{W}$. long, in one haul of the dragnet no less than I03 I fishes were taken from a depth of 450 metres. The chief surface fish noted in M. Filhol's very interesting papers, which are in course of publication in our French contemporary La Nature (to the editor of which journal we are in debted for the illustrations accompanying this notice), were the well-known shark (Charcharias glaucus), very common between the Senegal coast and the Cape de Verde Islands; its strange attendant fish, the so-callet pilot fish (Naucrates ductor), and the very curious and odd-looking fish of the Sargassum Sea, Antennarius marmoratus. It is noted that not only were the pilot fishes never molested by the shar'ss but that they constantly swam around them, sometimes even they were seen placing themselves against the shark's sides between their pectoral fins. Many observations were made on the strange Antennarius, the colour of whose body so closely approaches to that of the alga amidst which it lives that it enables these fish to approach almost unseen, and so quite easily take their prey. It is not, however, altogether unworthy of remark that this prey, consisting for the most part of small crustacea and mollusks, is also of the same general shade of colour as the mass of the weed, so that the assuming of this uniform dull tinge of colour must mean a heightened danger to some of these forms of life.

The great interest, however, of the fish captures of the Talisman centres in the remarkable forms taken from the depths of the sea, which were both considerable in the number of individuals and in the newness of the forms. The question of whether certain fish inhabit certain zones of depths was closely considered, and is answered in the affirmative. These zones are of very considerable depth, varying from 600 to over $36 ; 0$ metres, and in bringing up specimens from such areas of great pressure these suffer immensely through the phenomena caused by the rapid decompression of the air, the more remarkable effects being dilatation of the swim bladder, the eyes being squeezad out of their orbits, and the scales clothing the body are shed. In some cases even the fish $\mathbf{s}$ body has become smashed into pieces. Notwithstanding all these phenomena, the area in depth of the distribution of many of the deep-sea fish is very considerable. Thus Alepocephalus rostratus is met with between a depth of 868 and that of 3650 metres; Scopelus maderensis, between 


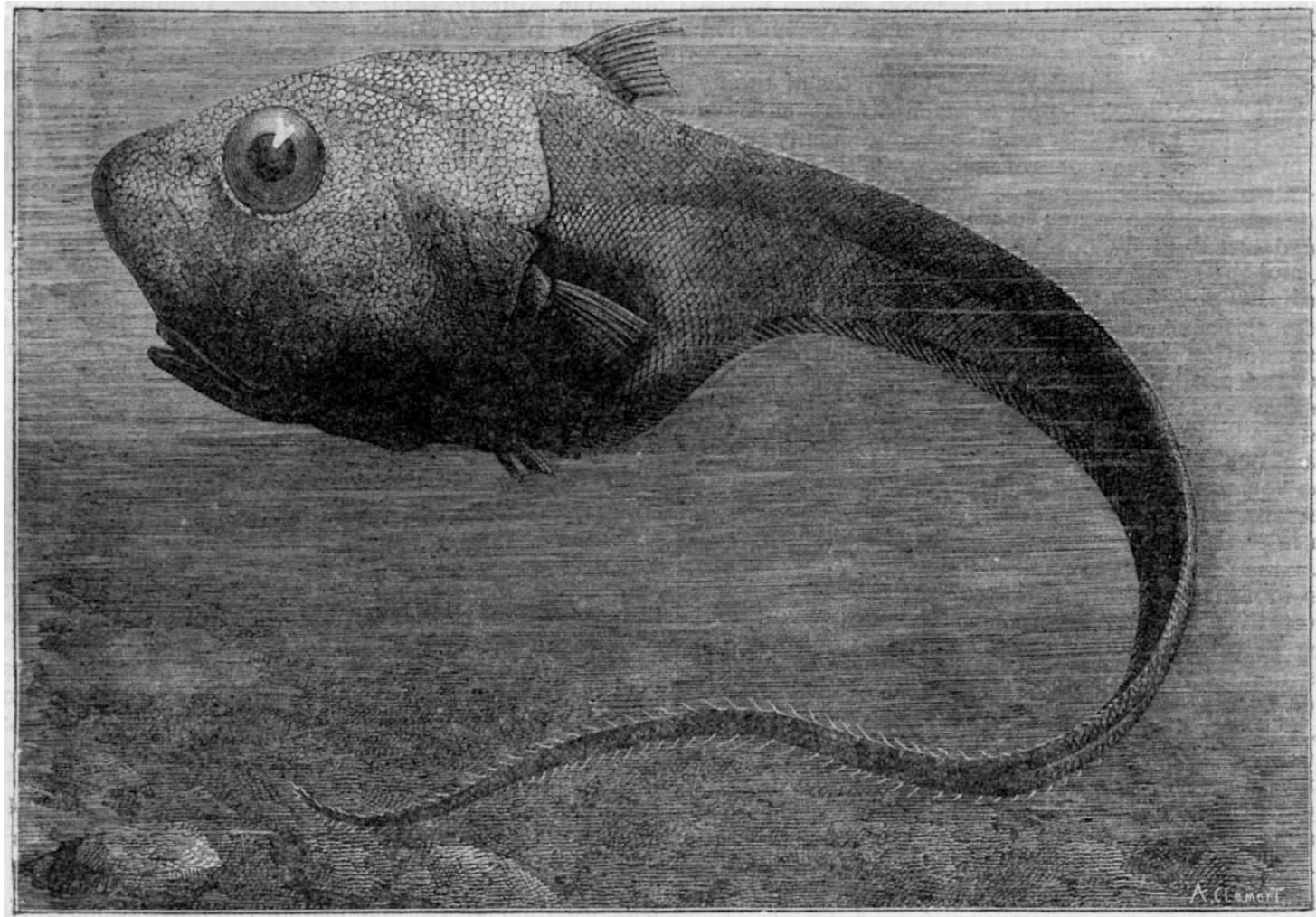

FIs. 1.-Macrurus globiceps, Vaill

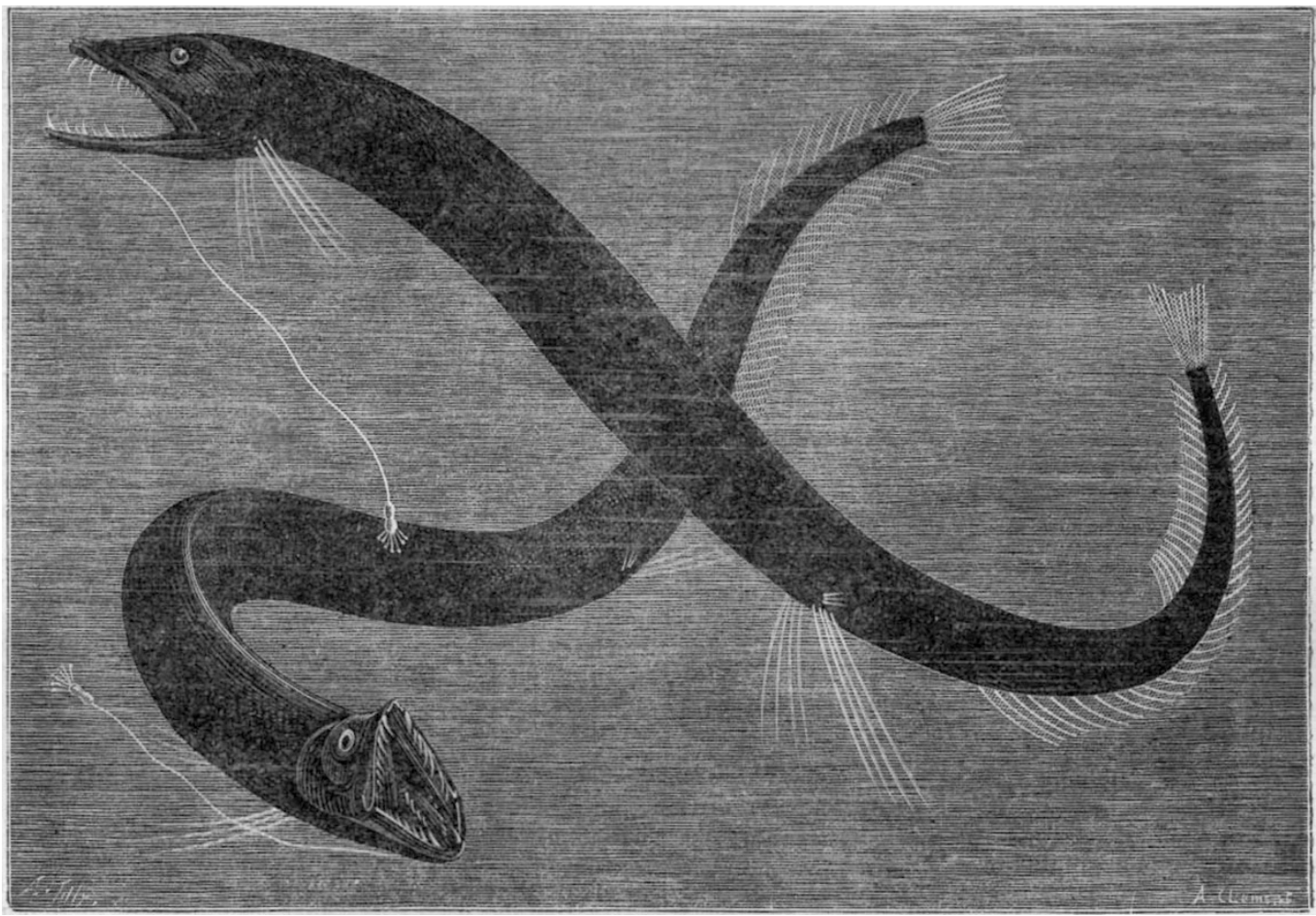

F1G. 2. -Eustomias obscurus, Vaill 
depths of 1090 and 3655 metres; Lepioderma macrops, between II 53 and 3655 metres; and Macrurus affinis, between 590 and 2220 metres. The explanation would seem to be not only that the organisation of these fishes is such as enables them to support the enormous pressures at the greater depths of the ocean, but that in the course of their movements of ascent and descent they proceed very slowly so as gradually to get accustomed to the alterations in pressure. These fishes are all flesh eaters, with well developed dental systems; the absence of light prevents the growth of marine algæ in these depths, and as a general rule all the fish found below 150 metres are of necessity predatory. These deep-sea fishes, as Dr. Günther reminds us, do not belong to any peculiar order, but are chiefly modified forms of surface types; some of these modifications being no doubt very extreme, but serving as indications not only of the struggle for existence, but also of the plasticness of the forms to adapt themselves to the extreme conditions under which they live. The most remarkable phenomena in connection with their deep-sea life is doubtless the tremendous pressure which has to be borne. No one seems to doubt but that these deep-sea forms live as active a life as surface forms, indeed their very appearance seems to indicate a swiftness and energy of movement not to be surpassed by surface swimmers; and we may believe that the abyssal pressure has a great deal to do with keeping their feebly calcareous bones and delicate muscular system compact and in a condition for effective use. The placid state of the water at these depths must also be borne in mindno storms affect them, and the extraordinary attenuation of some organs may be directly ascribed to this phenomenon. Thus Macrurus globiceps (Fig. I), which forms one of a family of deep-sea Ganoids, known as living at depths of from 600 to 2200 metres, and occurring in considerable variety and great numbers over all our oceans, is a new species, described by M. L. Vaillant as found at a depth of between $I 500$ and 3000 metres. Its body, globular in front, will be seen to be very greatly attenuated behind.

In some of the deep-sea fishes peculiar organs, unknown for the most part among surface fishes, are to be found; these are sometimes "more or less numerous, round, showing mother-of-pearl coloured bodies embedded in the skin"; in some fish these are to be met with on the head, or near the eyes, or along the sides and back. Dr. Günther informs us that of these strange bodies the following hypotheses are possible: (I) all these different organs are accessory eyes; (2) only those having a lens-like body in their interior are sensory, those with gland-like structure are not sensory but are phosphorescent; and (3) all are producers of light. Many serious objections can be urged against the first view. Some of the fish with immense eyes have these bodies, otbers without eyes want them, while as to glandular bodies being sense organs this is not yet scientifically realisable. One seems therefore justified in adopting the middle hypothesis, and though on first thought it secms strange that fish with large eyes should have accessory eyes, yet Dr. Günther's supposition may be the true one -that there are light producers behind the lenses, and that these latter may act the part of "bull's-eyes" in a lantern. This form of "light organ" might constitute a very deadly trap for prey, one moment shining it might attract the curiosity of some simple fish, then extinguished the simple fish would fall an easy prey.

Long filamentous organs are to be met with showing apparently a brilliant type of phosphorescence. Among the many curious forms of development of these tactile organs to be met with, one of the most singular is that to be seen on a fish referred by M. L. Vaillant to a new genus and species found at a depth of 2700 metres, and represented in the annexed woodcut (Fig. 2). In this forin (Eustomias obscurus) the tactile organ takes the appearance of a long filament, which is placed underneath the lower jaw, and which ends in an inflated and rayed knob-like phosphorescent mass.

Another peculiarity now well known in deep-sea fishes is the enormous development of the mouth and stomach of these fish. In the genus Melanocetus and in Chiasmodus the capacity of the stomach is such that it can contain prey twice the size of the fish which swallowed it, and perbaps the largest gape of jaws known is that of Eurypharynx pelecanoides. The greatest depth at which a fish was taken during the cruise of the Talisman was 4255 metres; the fish was Bythytes crassus: but it will be remembered that during the Challenger Expedition a specimen of Bathyopis ferox was taken at a depth of 5000 metres.

We hope again to have the opportunity of referring to other of the deep-sea forms taken by the Talisman.

\section{ANCIENT JAPAN}

THIS volume contains a literal translation of the oldest Japanese book in existence, accompanied by introductions, notes, and appendices, and is beyond doubt the most learned and remarkable work which European scholarship has yet produced from Japan. Of the many important propositions on the early history of the Japanese race established by it we shall have to speak later on; but of the work itself it may be said now that the translator claims it to be "the earliest authentic connected literary product of that large division of the human race which has been variously denominated Turanian, Scythian, and Altaïc, and it even precedes by at least a century the most ancient extant literary compositions of non-Aryan India." Indeed more than this may be said ; for if the claim of Accadian to be an Altaic language be not substantiated, not only the archaic literature of Japan (to which the Kojiki belongs), but also its classical literature, precedes by several centuries the earliest extant documents of any other Altaïc tongue. This alone would render the work an object of much interest, but it derives additional importance from its contents as well as from the period at which it was written. It is the earliest record of the language, customs, mythology, and history of ancient Japan, and soon after the date of its compilation, as Mr. Chamberlain points out, most of the salient features of distinctive Japanese nationality were buried under a superincumbent mass of Chinese culture; it is therefore to these "Records" and one or two other ancient works that the investigator must look if he would not be misled at every step into attributing originality to modern customs and ideas which have simply been borrowed wholesale from the neighbouring continent. It appears beyond doubt that, though the work existed in tradition for some years before that period, it was not committed to writing till the year 7I2 of our era, and from it a picture can be formed of the Japanese of that remote epoch. It is to the sections devoted by the translator to the manners and customs of the early Japanese and their political and social ideas that we propose to direct special attention now.

As pictured, then, in these "Records," the Japanese of the mythical era had emerged from the Stone Age and from the savage state. They were acquainted with the use of iron for weapons of the chase, such as arrows, swords, knives; but there is a curious silence about ordinary implements, such as axes and saws, though they had the fire-drill, pestle and mortar, wedge, and shuttle for weaving. The art of sailing appears to have been quite unknown, but boats for use on the inland lakes are mentioned. As would naturally be expected, the population was scattered along the seashore and on the banks

Transactions of the Asiatic Society of Japan, vol. x. Supplement.
Translation of the "Kojiki" or "Records of Ancient Matters." By Basil Translation of the "Kojiki" or "Recor
Hall Chamberlain. Yokohama, 1883 . 